\title{
Effect of Rapid Preheating on the Caking Properties of Coals
}

\author{
Kiyoshi FUKADA, ${ }^{1)}$ Shozo ITAGAKI ${ }^{2)}$ and Izumi SHIMOYAMA ${ }^{11}$ \\ 1) Steel Research Lab. Fukuyama, JFE Steel Corp., 1 Kokan-cho Fukuyama 721-8510 Japan. E-mail: k-fukada@jfe-steel.co.jp \\ 2) JFE Techno-Research Corp.
}

(Received on June 19, 2006; accepted on August 25, 2006)

\begin{abstract}
In order to obtain fundamental data for rapid preheating process, the swelling and agglomerating behavior of coal particles and the thermoplastic behaviors of coal under various heating conditions were investigated with a fluidized bed apparatus and a rapid heating plastometer.

Coal particles undergoing pyrolysis in $\mathrm{N}_{2}$ or $\mathrm{CO}_{2}$ atmosphere at a heating rate of $300^{\circ} \mathrm{C} / \mathrm{min}$ were filmed using a high-speed camera. The swelling and agglomerating behavior of them were evaluated by image analysis. Coal particle started to increase its size slightly around $350^{\circ} \mathrm{C}$ and expanded dramatically. Then coal agglomeration occurred around $420^{\circ} \mathrm{C}$. Coal swelling and agglomerating behavior was influenced by coal property and atmospheric condition. Especially $\mathrm{CO}_{2}$ atmosphere inhibited dilatation and agglomeration.

As the plasticity behavior of coal, minimum apparent viscosity and all characteristic temperatures corresponding to softening, maximum fluidity and resolidification state same as Gieseler method were measured by a rapid-heating plastometer. Coal plasticity was strongly dependent upon the heating conditions. For example, it was clarified that there existed an optimum rapid preheating temperature and that temperature, which had to be less than the softening temperature of Gieseler test, was related to coal rank. Moreover it was suggested that rapid heating effect was improved with the increase of the H/C atomic ratio of raw coal.
\end{abstract}

KEY WORDS: coal; coke; swelling; plasticity; rapid preheating; SCOPE21.

\section{Introduction}

Almost all of coke ovens in Japan were built around the high-growth period of the 1970s and they have more than 30 years in the average working life. It is predicted that the steel industry in Japan will face serious coke shortages at the outset of this century if they end their lives one after another without renewal. ${ }^{1)}$ But their renewal with conventional system is quite difficult because conventional coke ovens have problems in coal resource flexibility, productivity, energy saving and environmental protection. To solve these problems, the development of the innovative cokemaking process, SCOPE2 $1^{2-4)}$ (Super Coke Oven for Productivity and Environmental enhancement toward the 21 st century) was carried out as a ten-year research program (1994-2003) by member companies in the Japan Iron and Steel Federation.

One of the development objectives of SCOPE21 is the establishment of technologies for effective utilization of coal resources. That is, in order to raise the blending ratio of slightly caking coal dramatically, coal caking quality is upgraded by rapid heating in the coal pretreatment process. Of course, this new technology has many technical assignments. For example, an unequal heat history caused by coal size distribution, adherence of coal particles in a heating unit and an unclear of optimum rapid heating conditions etc. are serious problems. Recently many investigations have been conducted to make clear the basic phenomenon of coal caking property; the influence of rapid heat treatment on coal particle behavior and coal thermoplasticity.
It is important to understand the relationship between the caking property of coal particle and its heating characteristic. Basic heating characteristics in a rapid heating process were estimated by the analysis of the result obtained by pilot-plant tests and calculations by simulation model. Gas flow heating tower was assumed as a heating system. As a result, the heating-up performance of the coal rapid heating process was clarified. ${ }^{5)}$ On the one hand, it is undesirable for coal particles to break into fine powder in preheating process so that the effect of rapid heating conditions on the heat crack of coal particles was studied. And it was indicated that drying coal particle in advance could prevent the heat crack of coal particles. $\left.{ }^{6}\right)$ The influence of heating conditions on adherence of coal particles was also investigated from the aspect of handling ability. The change of bed height at fluidized bed was estimated since it was shown that the swelling and agglomeration behavior of coal particles increased with the rise of heating rate. ${ }^{7)}$

Some investigations considering coal and coke quality improvement by rapid heating treatment had been carried out. In order to make clear the effect of rapid heat treatment on thermoplastic behavior, experiments using a needle penetrater were conducted. It was found that the thermoplasticity of coal was enhanced when the coal was rapidly preheated to $330-380^{\circ} \mathrm{C}$, even if the normal heating rate $\left(3^{\circ} \mathrm{C} / \mathrm{min}\right)$ was applied through the following thermoplastic stages. ${ }^{8)}$ The effect of rapid heating on coke quality was ascertained in experiments on small-scale facilities. It was shown that the rapid heating treatment of coal nearly up to softening temperature raised drum index and a optimum 
Table 1. Properties of coals used in the experiments.

\begin{tabular}{|c|c|c|c|c|c|c|c|c|c|c|c|c|}
\hline \multirow{2}{*}{$\begin{array}{l}\text { Coal } \\
\text { brand }\end{array}$} & \multicolumn{2}{|c|}{$\begin{array}{l}\text { Proximate analysis } \\
\text { (mass } \% \text { d.b.) }\end{array}$} & \multicolumn{4}{|c|}{$\begin{array}{l}\text { Ultimate analysis } \\
\text { (mass\% d.a.f.) }\end{array}$} & \multicolumn{4}{|c|}{$\begin{array}{l}\text { Gieseler } \\
\text { properties }\end{array}$} & \multirow{2}{*}{$\begin{array}{l}\overline{\text { Ro }} \\
(\%)\end{array}$} & \multirow{2}{*}{$\begin{array}{r}\text { Total } \\
\text { inert } \\
(\%)\end{array}$} \\
\hline & $\mathrm{ASH}$ & VM & C & $\mathrm{H}$ & $\mathrm{N}$ & S & $\mathrm{ST}^{* 1}$ & $\mathrm{MFT}^{* 2}$ & $\mathrm{RT}^{* 3}$ & LogMF & & \\
\hline Coal A & 8.5 & 39.5 & 81.5 & 5.6 & 2.0 & 0.9 & 398 & 440 & 465 & 1.73 & 0.68 & 22.3 \\
\hline Coal B & 8.5 & 33.4 & 83.0 & 5.1 & 1.9 & 0.5 & 396 & 433 & 449 & 1.18 & 0.69 & 35.8 \\
\hline Coal C & 5.7 & 37.1 & 81.4 & 5.4 & 2.2 & 0.4 & 398 & 430 & 454 & 0.48 & 0.70 & 20.6 \\
\hline Coal D & 8.3 & 32.9 & 82.7 & 5.1 & 1.5 & 0.4 & 397 & 421 & 449 & 1.56 & 0.70 & 35.2 \\
\hline Coal E & 10.9 & 33.6 & 83.1 & 5.3 & 2.1 & 0.6 & 410 & 429 & 452 & 0.30 & 0.71 & 41.5 \\
\hline Coal F & 9.6 & 32.6 & 83.2 & 5.3 & 1.8 & 0.4 & 402 & 427 & 448 & 2.01 & 0.71 & 25.2 \\
\hline Coal G & 8.6 & 35.2 & 82.5 & 5.6 & 1.9 & 0.5 & 394 & 429 & 459 & 2.16 & 0.71 & 24.3 \\
\hline Coal H & 8.2 & 36.4 & 82.8 & 5.6 & 2.0 & 0.7 & 396 & 434 & 463 & 1.93 & 0.72 & 20.5 \\
\hline Coal I & 8.8 & 34.6 & 83.3 & 5.4 & 1.9 & 0.5 & 393 & 435 & 459 & 2.25 & 0.73 & 26.8 \\
\hline Coal J & 8.4 & 38.9 & 82.5 & 5.7 & 1.9 & 0.5 & 397 & 432 & 456 & 1.94 & 0.74 & 19.7 \\
\hline Coal K & 6.1 & 34.1 & 83.5 & 5.1 & 2.1 & 0.6 & 401 & 431 & 443 & 0.90 & 0.74 & 38.0 \\
\hline Coal L & 10.0 & 32.5 & 83.2 & 5.2 & 1.8 & 0.7 & 405 & 435 & 456 & 1.72 & 0.76 & 27.9 \\
\hline Coal M & 10.6 & 33.3 & 82.9 & 5.5 & 2.0 & 0.6 & 394 & 431 & 457 & 2.28 & 0.79 & 19.9 \\
\hline Coal N & 8.9 & 24.6 & 87.6 & 5.0 & 1.9 & 0.5 & 406 & 456 & 494 & 2.88 & 1.10 & 37.1 \\
\hline
\end{tabular}

*1:Softening Temperature, *2:Maximum Fluidity Temperature, *3:Resolidification Temperature

preheating temperature existed. ${ }^{9,10)}$

Objectives of this study were to investigate the influence of rapid preheat treatment on coal caking properties, especially coal particle behavior itself and thermoplasticity. Firstly the effect of coal brand and atmosphere conditions was studied and coal particle behavior under rapid heating was examined. And then so as to obtain the optimum preheat treatment conditions, the relationship between heating conditions and thermoplastic behavior were analyzed by using the new plastometer we developed.

\section{Experimental}

\subsection{Coal Samples}

The characterization data and analyses of the coals used are given in Table 1. Thirteen different slightly caking coals (Coal A to Coal M) and one caking coal (Coal N) were selected. Slightly caking coal in this study was defined $\mathrm{Ro}<0.9$ and $\log (\mathrm{MF} / \mathrm{ddpm})<2.5$, or $\log (\mathrm{MF} / \mathrm{ddpm})<0.5{ }^{11)}$ The coal under test was air-dried and reduced to a predefined particle size using a pestle just before the examination.

\subsection{Direct Observation of Particle Behavior during Rapid Heating}

A new experimental setup was assembled to observe the particle behavior during heating in reference to the previous study. ${ }^{7)}$ Schematic illustration of this apparatus is shown in Fig. 1. The reactor vessel is made of quartz and it has double tube structure for preheating carrier gas. The inner tube with $20 \mathrm{~mm}$ internal diameter has 200-mesh filter. As a heater, gold furnace (Ishikawa Trading Co., Ltd.) was installed in this study. It consists of a heating element and a gilded quartz tube so that sample inside can be observed during heating.

The sample to be studied was ground between 0.42 to $0.50 \mathrm{~mm}$. Five grams of the sample in each run was charged into the vessel and fluidized under $\mathrm{N}_{2}$ or $\mathrm{CO}_{2}$ atmosphere at a constant flow rate $5 \mathrm{NL} / \mathrm{min}$ at room temperature in advance. Gas flow rate $5 \mathrm{NL} / \mathrm{min}$ was determined on the

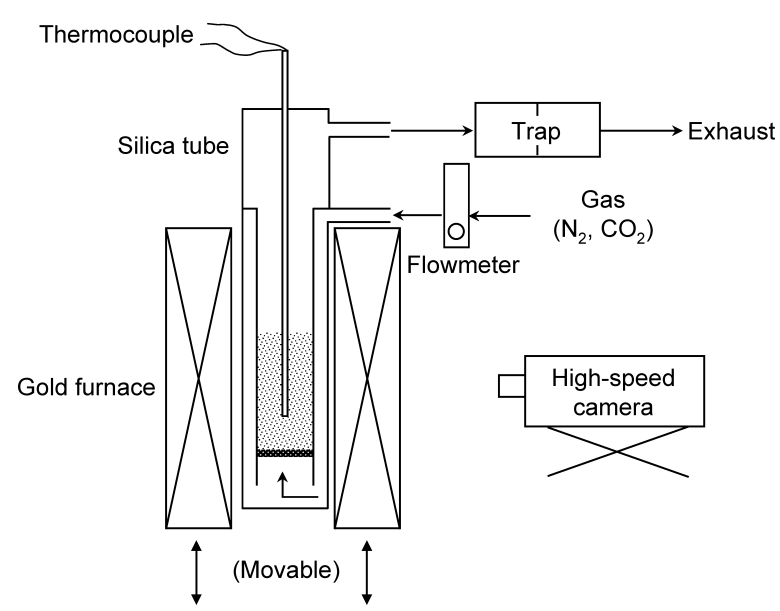

Fig. 1. Schematic illustration of fluidized heating apparatus.

ground that fluidization condition could be held during heating. $\mathrm{CO}_{2}$ gas atmosphere was tested to assume the utilization of combustion gas for heating.

After coal particles were fluidized, they were heated rapidly by bringing up the furnace, which was preheated to $900^{\circ} \mathrm{C}$ in advance separately from the vessel. Two thermocouples were inserted in the center of coal bed before and during fluidization and the temperature of gas-coal mixture was measured.

Coal particles were photographed undergoing pyrolysis in a $\mathrm{N}_{2}$ or $\mathrm{CO}_{2}$ atmosphere by a high-speed camera through the quartz wall of a gold furnace. Both swelling behavior and agglomeration behavior were determined using an image processing software.

In order to evaluate the degree of coal particles swelling behavior, relative particle size, which was defined "Each particle size/Initial average size", was used. Twenty particle images in each temperature were imported at random and binary image was created to separate background from coal particle. Moreover, when more than 2 coal particles adhered obviously, it was defined agglomeration temperature. 


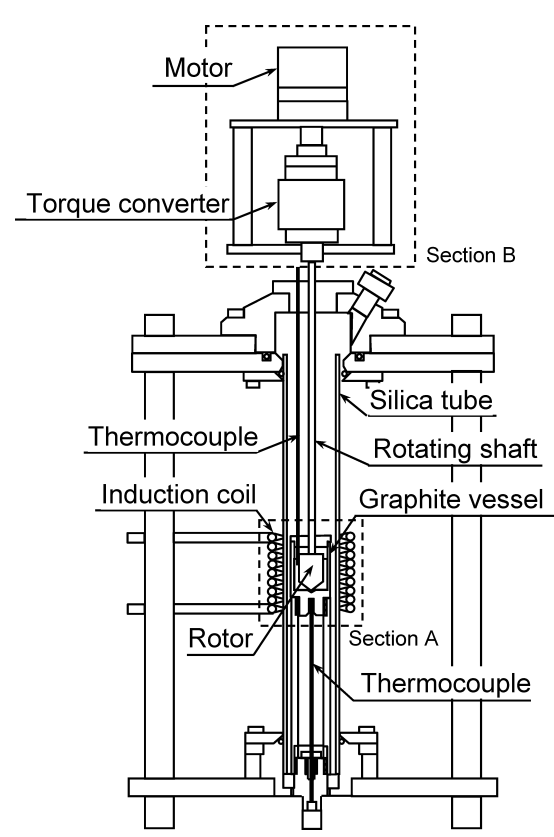

Fig. 2. Schematic illustration of rapid-heating plastometer.

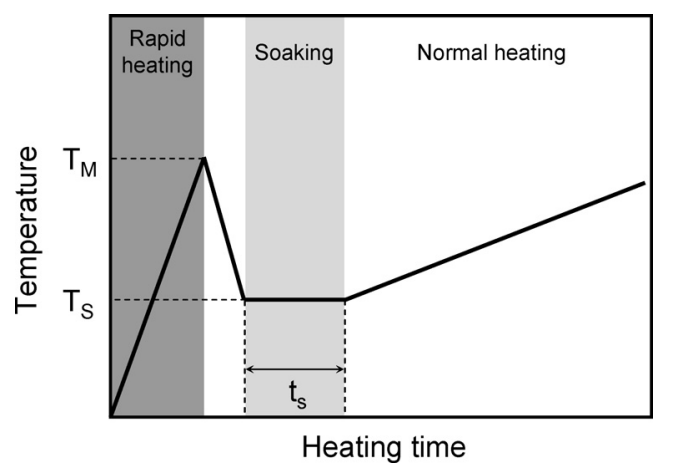

Fig. 3. Heating pattern of coal in the rapid-heating plastometer test.

\subsection{Thermoplasticity Measurement by a Rapid-heat- ing Plastometer}

A rapid-heating plastometer used in this investigation is shown in Fig. 2. This instrument was developed for evaluation of coal thermoplasticity before and the method of test and analysis has been described in detail elsewhere. ${ }^{12)}$ Section $\mathrm{A}$ is a heating part and section $\mathrm{B}$ is a torque measurement part. The distance between section A and B was designed considering the heat resistance of a torque detector. Coal sample is charged to between graphite vessel (ID $14 \mathrm{~mm}$ ) and rotor (OD $12 \mathrm{~mm}$ ) with the defined density, and the vessel is set up in the high-frequency induction furnace. Sample can be heated with a heating rate of $1800^{\circ} \mathrm{C} / \mathrm{min}$ at a maximum by heat conduction from the graphite wall heated up by high-frequency induction. Temperature is measured by two thermocouples of $1.0 \mathrm{~mm}$ diameter attached to a hole at the bottom of the chamber and passed into the coal layer. The thermoplastic behavior of coal can be estimated by shear stress detected by a torque converter.

As the shape of rotor, the shape of spinning top that combined the cylinder and the cone was adopted. Space between a chamber and a rotor was filled with $1.0 \mathrm{~g}$ of coal with $0.85 \mathrm{~g} / \mathrm{cm}^{3}$ having a particle size smaller than 60 mesh. Figure 3 presents a heating pattern of coal in the

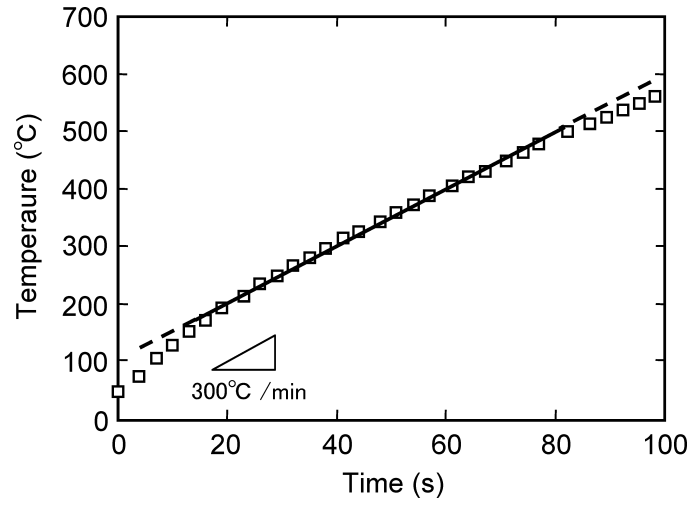

Fig. 4. Heating pattern in the center of coal bed.

rapid-heating plastometer test. The coal sample was heated up to maximum preheating temperature $\left(T_{\mathrm{M}}\right)$ ranging from 350 to $420^{\circ} \mathrm{C}$ with a heating rate of $1000^{\circ} \mathrm{C} / \mathrm{min}$ and thereafter cooled down to soaking temperature $\left(T_{\mathrm{S}}\right) 250$ or $300^{\circ} \mathrm{C}$ straight away. Rapid heating and cooling were carried out to clarify whether rapid heating reaction was irreversible. Soaking time $\left(t_{\mathrm{s}}\right)$ was varied from 0 to $1 \mathrm{~h}$. After that coal was heated again at $10^{\circ} \mathrm{C} / \mathrm{min}$, coinstantaneously the stirrer was rotated at a constant angular velocity with $0.10 \mathrm{rev} / \mathrm{min}$ and torque was measured during the coal softened. The torque value was converted to an apparent viscosity according to the following equation:

$$
\eta=\frac{M}{2 \pi \omega} /\left\{\frac{h}{\left(1 / r_{\mathrm{i}}^{2}-1 / r_{\mathrm{o}}^{2}\right)}+\frac{R^{3}}{3 \theta}\right\}
$$

where $\eta$ is the apparent viscosity, $M$ is the torque, $\omega$ is the angular velocity, $h$ is height of cylinder, $r_{\mathrm{i}}$ is the inner cylinder, $r_{\mathrm{o}}$ is the outer cylinder, $R$ is the cone radius and $\theta$ is the angle between cone and base.

Softening, maximum fluidity and resolidification temperatures were measured as the characteristic temperatures of coal plastic properties based on the published method. ${ }^{12)}$

\section{Results and Discussions}

\subsection{Coal Particles Behavior by Rapid Heating}

\subsubsection{Assessment of Temperature}

The result of temperature measurement is shown in Fig. 4. The temperature of gas-coal mixture rose up rapidly, as soon as the gold furnace was brought up. At the temperature span between $200^{\circ} \mathrm{C}$ and $500^{\circ} \mathrm{C}$, the coal bed could be heated with a constant heating rate approximately $300^{\circ} \mathrm{C} / \mathrm{min}$.

\subsubsection{Swelling Behavior}

Figure 5 shows the influence of the heat treatment temperature on the relative particle size of Coal K (slightly caking coal) and Coal $\mathrm{N}$ (caking coal). An initial period of heating, no particle size change was observed. Coal particles started to increase their size slightly around $350^{\circ} \mathrm{C}$. This temperature was lower than the softening temperature of Gieseler test. This may be in part due to gas-coal temperature lagging behind coal particle temperature itself. Without particle adhesion, the expansion rate of coal particle became fast and the size grew to 1.2-1.4 times its initial size 


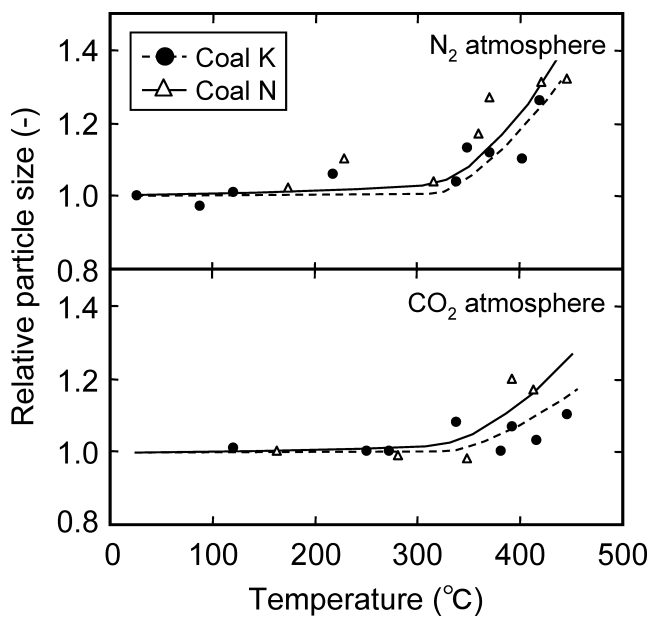

Fig. 5. Variation of relative coal particle size with temperature.

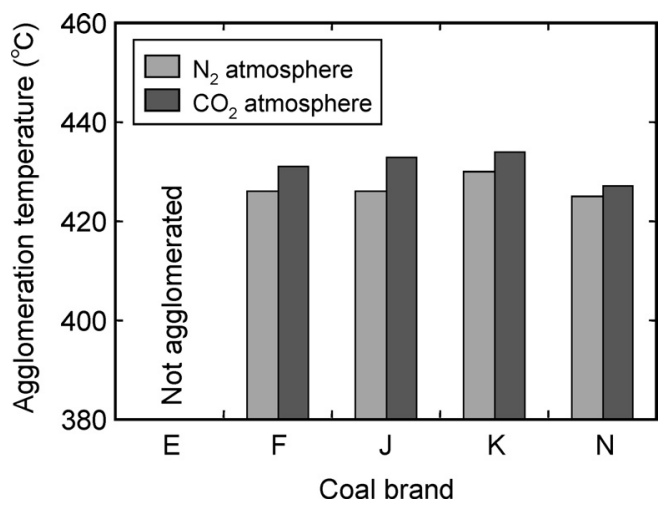

Fig. 6. Agglomeration temperature of coals.

and then coal agglomeration occurred. The degree of particle change was similar to the result of bed expansion under rapid heating with a fluidized bed reactor. ${ }^{7)}$

The swelling behavior of coal particles was affected by coal property and atmospheric condition. The relative particle size, immediately before agglomeration, of Coal $\mathrm{N}$ was larger than that of Coal K. This result seemed to correspond to coal plastic properties, for example Gieseler fluidity. And the expansion of coal particles under $\mathrm{CO}_{2}$ gas was smaller than under $\mathrm{N}_{2}$ gas. This result suggests the possibility that coal plastic property is deteriorated with the increase of $\mathrm{CO}_{2}$ partial pressure. It is considered that $\mathrm{CO}_{2}$ molecule adsorption affected coal plasticity negatively or oxygen atom remained in coal for longer period since $\mathrm{CO}_{2}$ gas evolution was delayed at the initial stage of pyrolysis.

\subsubsection{Agglomerating Behavior}

Figure 6 presents agglomeration temperatures of coal particles in each run. Coal $\mathrm{E}$ was hardly dilated during heating and was not agglomerated at all. But Coal F, J, K and $\mathrm{N}$ were agglomerated around $420^{\circ} \mathrm{C}$ and high fluidity coal tended to be agglomerated at lower temperature. This result indicates that there is a high possibility for coal particles to be agglomerated if coal has enough thermoplasticity to swell.

Agglomeration temperature under $\mathrm{CO}_{2}$ gas was higher than that under $\mathrm{N}_{2}$ gas. But the order of agglomeration temperature was not dependent on atmospheric conditions. It is considered that $\mathrm{CO}_{2}$ molecule adsorption or the delay of

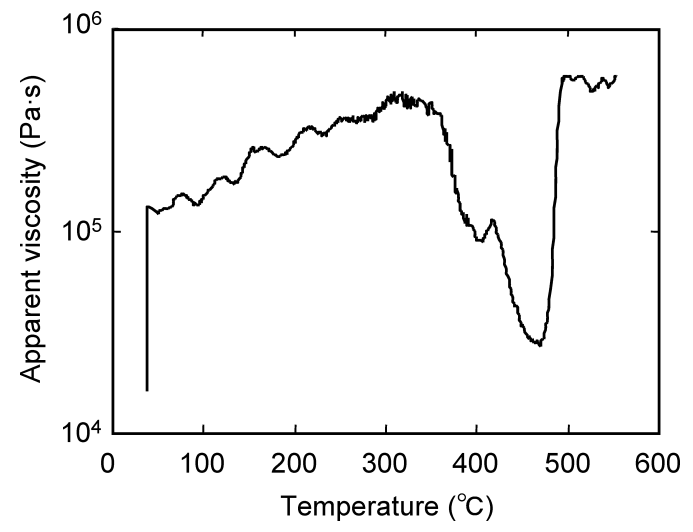

Fig. 7. Apparent viscosity curve at $10 \mathrm{~K} / \mathrm{min}(\mathrm{Coal} \mathrm{N})$.

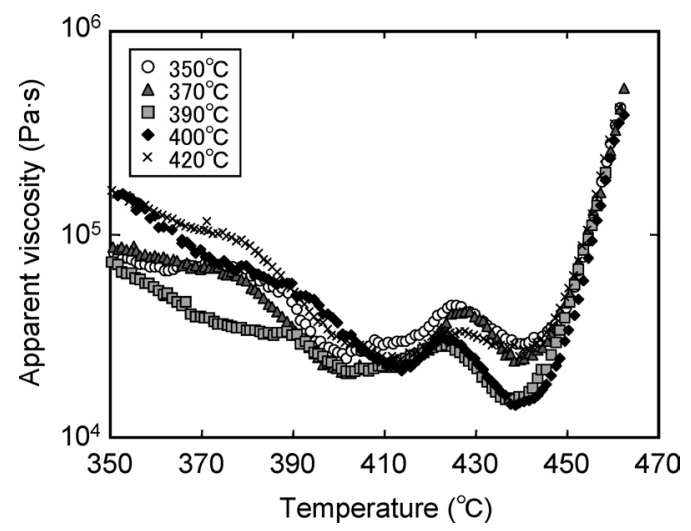

Fig. 8. Apparent viscosity curve of rapid heated coal at $10 \mathrm{~K} / \mathrm{min}$ (Coal I).

$\mathrm{CO}_{2}$ gas evolution at the initial stage of pyrolysis with the increase of $\mathrm{CO}_{2}$ partial pressure reduced coal plasticity properties.

\subsection{Thermoplastic Behavior of Rapid Heated Coal \\ 3.2.1. Typical Rapid-heating Plastometer Results}

Figure 7 presents typical data obtained at a rotational speed of $0.1 \mathrm{rev} / \mathrm{min}$ with a heating rate $10 \mathrm{~K} / \mathrm{min}$ constant. Torque value detected by a torque converter was converted to apparent viscosity by Eq. (1).

As the temperature increases, the apparent viscosity increased and then started to decrease to a low value, due to gas evolution and liquid formation. After a period at a low level, the viscosity of the molten coal rose to a high value, due to progressive resolidification.

\subsubsection{Effect of Preheating Temperature}

The apparent viscosity curve of coal in a condition where the preheat treatment temperature ranged from 350 to $420^{\circ} \mathrm{C}$ is shown in Fig. 8. There was a big difference in minimum apparent viscosity. The plasticity of coal preheated to 390 and $400^{\circ} \mathrm{C}$ was improved distinctly, whereas minimum viscosity temperature was almost same. This result suggests that there exists optimum preheat treatment temperature to improve coal thermoplasticity.

The effect of maximum preheating temperature $\left(T_{\mathrm{M}}\right)$ on a minimum apparent viscosity in different coal brands is shown in Fig. 9. A minimum apparent viscosity of coal with preheat treatment was lower than that of coal without preheat treatment in each coal brand, even though preheated 

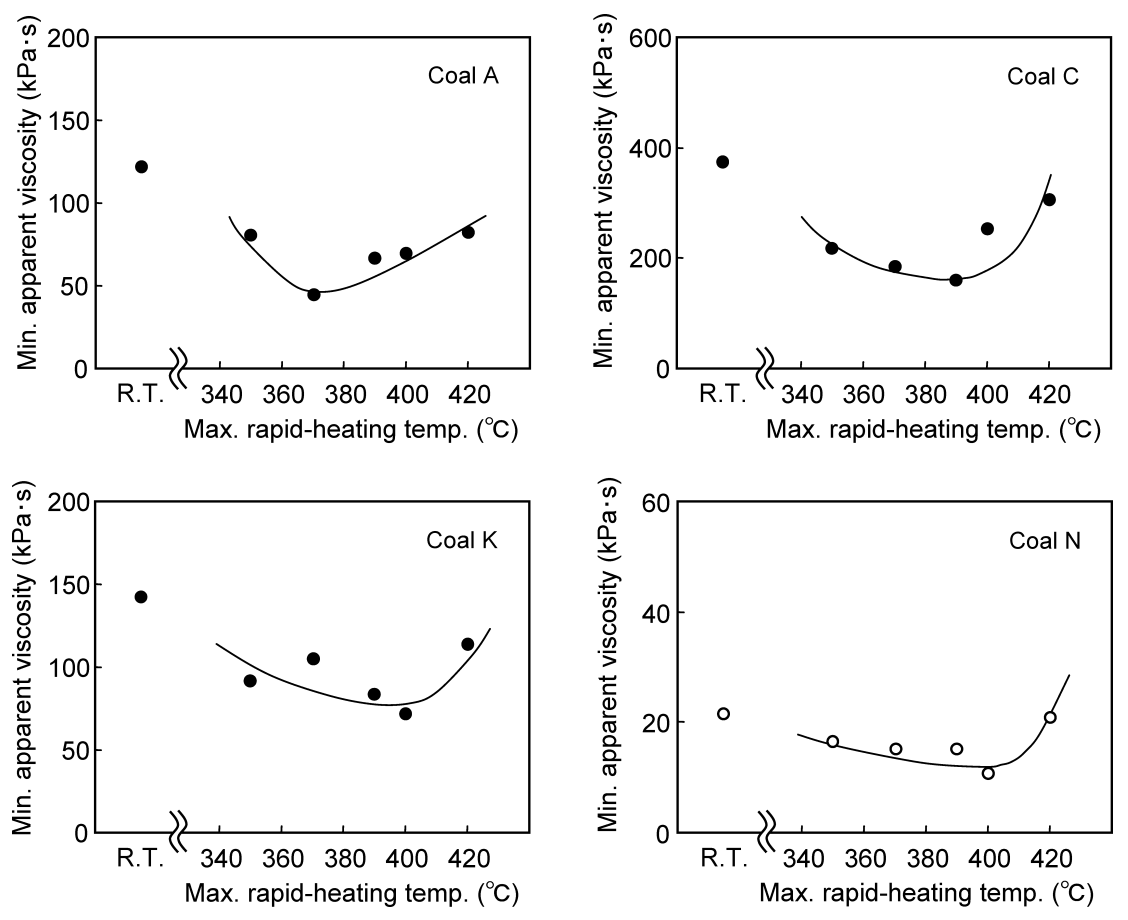

Fig. 9. Effect of maximum rapid-heating temperature on minimum apparent viscosity.

coal was cooled down to soaking temperature $\left(T_{\mathrm{S}}=300^{\circ} \mathrm{C}\right)$ before normal heating. This result indicates the effect of rapid heating on coal plasticity is irreversible.

There have been some reports concerning with irreversible phenomena before major thermal decomposition of coal. For example, Y. Yun and E. M. Suuberg ${ }^{13)}$ discussed the physical relaxation of coal structure and irreversible process in accordance with the result of differential scanning calorimetry and solvent swelling measurement. According to their experimental result, some coals exhibited distinctly endothermic peaks before major thermal decomposition temperature (around $350^{\circ} \mathrm{C}$ ) and their peaks were more apparent at higher heating rates, however these peaks were not observed from the samples after cooling. They stated that these endothermic changes indicated the structural relaxation of coal and these phenomena were irreversible. In addition, M. Sasaki et al. ${ }^{9)}$ analyzed rapid preheated samples after cooling by CRAMPS (Combined Rotation and Multi Pulse Spectroscopy) method. With the increase of heat treatment temperature by rapid heating, the concentration of hydrogen-bonded $\mathrm{OH}$ group decreased and longitudinal relaxation time became large. They concluded the molecular structure of coal was relaxed by rapid preheat treatment. It is considered that these study results are hints of the irreversible phenomena of coal thermoplasticity and the elucidation of this mechanism is future task.

Figure 9 also shows that there existed optimum preheat treatment temperature to improve coal thermoplasticity and it was different in coal brand. Then, the relationship between coal rank and the optimum preheat treatment temperature of slightly caking coal, which was obtained by the relation between maximum rapid-heating temperature and minimum apparent viscosity, was plotted (Fig. 10). Coal rank is adopted as $\mathrm{x}$-axis since the structural relaxation temperature is dependent on coal rank. ${ }^{13)}$ Optimum preheating temperature rose with the increase of coal rank. And the optimum preheating temperature of every coal brand was

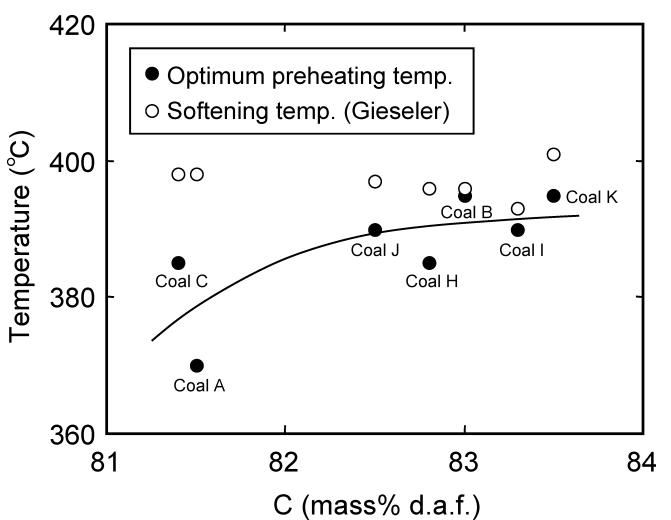

Fig. 10. Relationship between coal rank and characteristic temperatures.

lower than the soften temperature of Gieseler fluidity. It is considered that the structural relaxation occurs at temperatures lower than that for pyrolytic bond breakage. ${ }^{13)}$

\subsubsection{Effect of Coal Property}

It is expected that the effect of rapid preheat treatment on coal thermoplasticity is different in coal brands. The minimum apparent viscosity of coal without and with rapid heating is shown in Fig. 11. Preheating temperature $\left(T_{\mathrm{M}}\right)$ was $380^{\circ} \mathrm{C}$ with a heating rate of $1000^{\circ} \mathrm{C} / \mathrm{min}$, holding temperature $\left(T_{\mathrm{S}}\right)$ was $300^{\circ} \mathrm{C}$ and holding time $\left(t_{\mathrm{s}}\right)$ was $0 \mathrm{~h}$ constant. The minimum apparent viscosity of every tested coal with rapid preheating was lower than that of coal without rapid heating, and the thermoplasticity of very poor caking coals, coal $\mathrm{C}, \mathrm{E}$ and $\mathrm{K}$ were improved so much by pretreatment.

Figure 12 compares the characteristic temperatures (softening temperature, maximum fluidity temperature and resolidification temperature) of raw coal with those of rapid heated coal. The characteristic temperatures of rapid heated coal showed a tendency to be 2 or $3^{\circ} \mathrm{C}$ higher than those of 
raw coal. However, the difference was not so clear. This means the characteristic temperatures are not dependent on rapid heating before softening temperature.

The relationship between coal properties and the effect of rapid heating was investigated as shown in Fig. 13. Rapid heating effect was defined as the ratio of the difference between raw coal and rapid heated coal viscosity $\left(\eta_{0}-\eta\right)$ to raw coal viscosity $\left(\eta_{0}\right)$ (Eq. (2)).

$$
\text { Rapid heating effect }=\left(\eta_{0}-\eta\right) / \eta_{0}
$$

It is just conceivable that the behavior of hydrogen atom is one of the key to the effect of rapid preheat treatment since the concentration of hydrogen-bonded $\mathrm{OH}$ group and the longitudinal relaxation time change by rapid preheating. ${ }^{9)}$

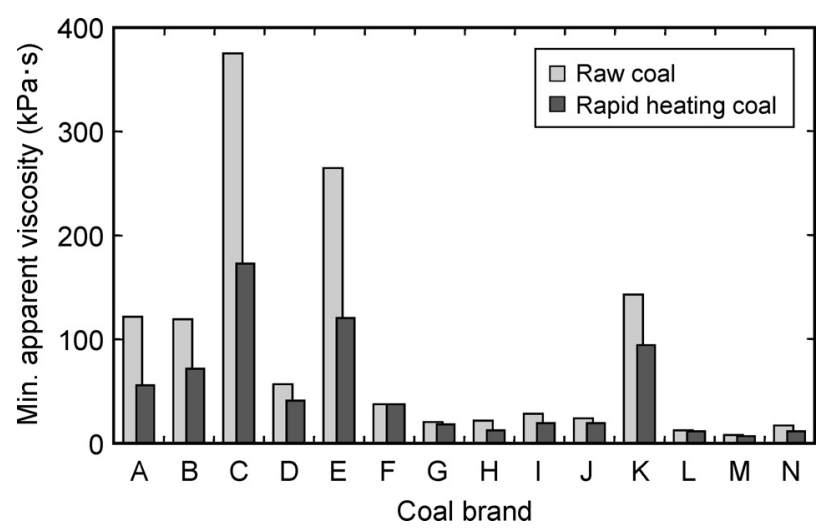

Fig. 11. Comparison of minimum apparent viscosity by different heating conditions.
So, $\mathrm{H} / \mathrm{C}$ atomic ratio was adopted for a dependent factor. On the other hand, atomic $\mathrm{H} / \mathrm{C}$ ratios are different among various macerals, that is, the $\mathrm{H} / \mathrm{C}$ of inertinite group is smaller than that of vitrinite group. But at the same time, the composition of maceral affects the thermoplasticity of coal. Therefore, total inert ratio was connected with the relationship between $\mathrm{H} / \mathrm{C}$ atomic ratio and rapid heating effect.

As shown in Fig. 13, the rapid heating effect correlated with $\mathrm{H} / \mathrm{C}$ atomic ratio and it was improved with the increase of $\mathrm{H} / \mathrm{C}$ atomic ratio. Moreover, the correlation shifted to left with the rise of inerts content.

It is inferred from this result that among various macerals, for example inertinite group and vitrinite group differ in rapid heating effect. Then it is necessary for the clarification of this hypothesis to investigate the influence of maceral content on the rapid heating effect in more detail.

\subsubsection{Effect of Temperature Holding Condition}

It is better to keep the temperature of coal at a higher level after rapid preheating from the aspect of energy saving. However, it is predicted that the thermoplasticity of coal will deteriorate gradually if it is kept around the beginning temperature of pyrolysis. Then the effect of temperature holding conditions on the thermoplastic behavior of coal was investigated.

Figure 14 shows the effect of soaking conditions on the property of rapid heated coal. Five coals (Coal D, E, F, G, L and $\mathrm{M}$ ) were used for investigation. Preheating temperature $\left(T_{\mathrm{M}}\right)$ was $380^{\circ} \mathrm{C}$ with a heating rate of $1000^{\circ} \mathrm{C} / \mathrm{min}$, hold-
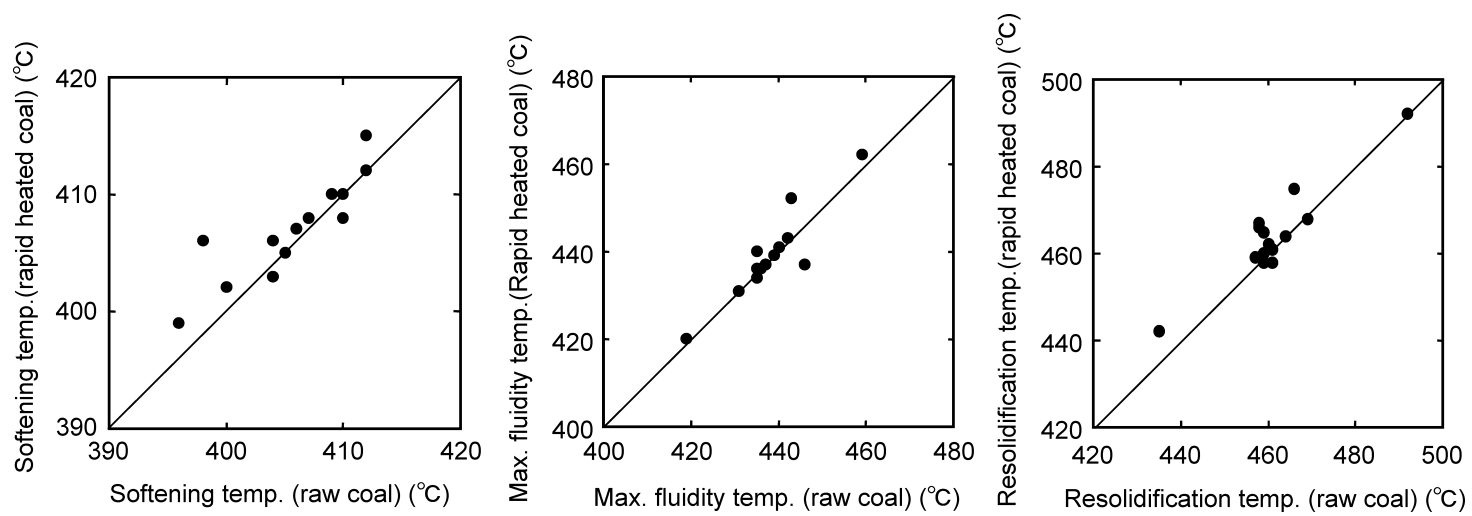

Fig. 12. Relationship between characteristic temperatures of raw coal and those of rapid heated coal.

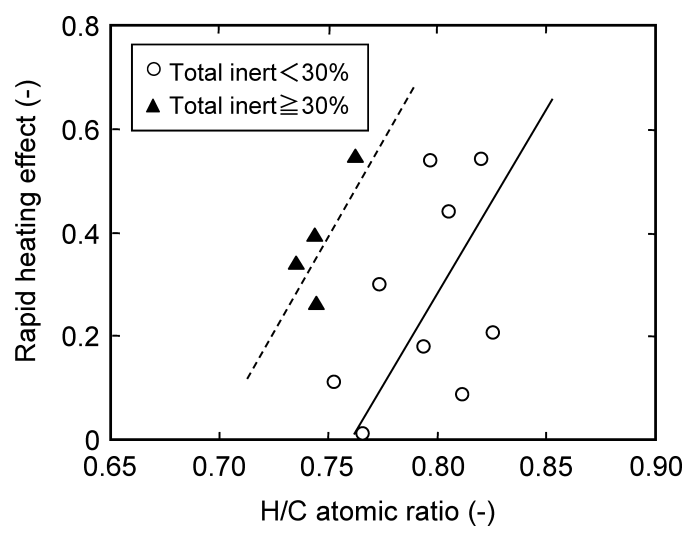

Fig. 13. Relationship between $\mathrm{H} / \mathrm{C}$ atomic ratio and rapid heating effect (slightly caking coal).

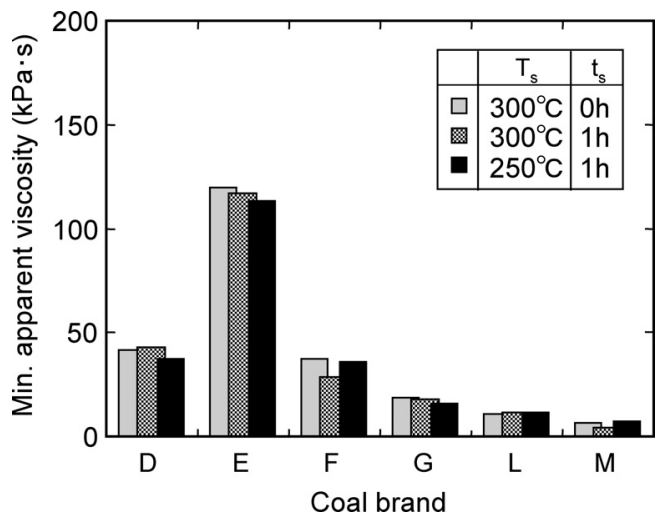

Fig. 14. Comparison of minimum apparent viscosity by different soaking conditions. 
ing temperature $\left(T_{\mathrm{S}}\right)$ was 300 and $250^{\circ} \mathrm{C}$, holding time $\left(t_{\mathrm{s}}\right)$ was 0 and $1 \mathrm{~h}$.

The minimum apparent viscosity of rapid preheated coal was not changed by soaking for $1 \mathrm{~h}$ at $300^{\circ} \mathrm{C}$. And if soaking temperature was lowered to $250^{\circ} \mathrm{C}$, a big change for coal thermoplasticity wan not observed.

It is clarified that the thermoplasticity of coal preheated rapidly was maintained at least $1 \mathrm{~h}$ in the case of $250-300^{\circ} \mathrm{C}$ holding temperature. This means the preheated coal can be reserved without quality change in hopper for a while.

\section{Conclusions}

The effect of rapid preheating on coal particle behavior and thermoplasticity was investigated and the following results were obtained.

(1) Coal swelling and agglomerating behavior was affected by coal property and atmospheric condition. For example, high fluidity coal tended to be agglomerated at lower temperature and $\mathrm{CO}_{2}$ atmosphere inhibited particle expansion and agglomeration.

(2) The viscosity of coal was improved by adequate rapid preheating conditions. The optimum rapid preheating temperature was related to coal rank. High rank coal had to be heated up to around $400^{\circ} \mathrm{C}$ rapidly. However, its temperature was less than softening temperature.

(3) Rapid heating effect was irreversible. It correlated with $\mathrm{H} / \mathrm{C}$ atomic ratio and total inert ratio. It was improved with the increase of $\mathrm{H} / \mathrm{C}$ atomic ratio.

(4) The thermoplasticity of coal preheated rapidly was maintained at least $1 \mathrm{~h}$ at $300^{\circ} \mathrm{C}$ under inert atmosphere.

\section{REFERENCES}

1) Y. Takizawa: Tetsu-to-Hagané, 78 (1992), 969.

2) K. Nishioka: Proc. 3rd Int. Cokemaking Cong., CRM Liège, (1996), 285.

3) H. Taketomi, K. Nishioka, Y. Nakashima, S. Suyama and M. Matsuura: Proc. 4th European Coke and Ironmaking Cong., ATS, Paris, France, (2000), 640.

4) K. Nishioka, H. Oshima, I. Sugiyama and H. Fujikawa: Tetsu-toHagané, 90 (2004), 614.

5) Y. Matsuda, M. Yokomizo, M. Sasaki and M. Matsuura: Tetsu-toHagané, 90 (2004), 648.

6) M. Nishimura and K. Amamoto: Tetsu-to-Hagané, 90 (2004), 634.

7) Y. Ohtsuka, Z. Wu, A. Tomita and S. Itagaki: Tetsu-to-Hagané, 90 (1996), 372.

8) K. Kato, M. Matsuura, M. Sasaki, M. Sakawa and I. Komaki: J. Jpn. Inst. Energy, 83 (2004), 868.

9) M. Sasaki, I. Komaki, M. Matsuura, K. Saito and K. Fukada: Ironmaking Conf. Proc., ISS, Warrendale, PA, (1998), 803.

10) M. Matsuura, M. Sasaki, K. Saito, K. Kato and I. Komaki: Tetsu-toHagané, 89 (2003), 565.

11) M. Matsuura, M. Sasaki, K. Kato and Y. Nakashima: Tetsu-toHagané, 90 (2004), 656.

12) K. Fukada, S. Itagaki and I. Shimoyama: Tetsu-to-Hagané, 90 (2004), 641.

13) Y. Yun and E. M. Suuberg: Fuel, 72 (1993), 1245. 